\title{
A COMUNIDADE DE PESQUISA DOS PAÍSES AVANÇADOS E A ELABORAÇÃO DA POLÍTICA DE CIÊNCIA E TECNOLOGIA
}

\section{Renato Dagnino}

\section{Introdução}

Este trabalho revisa um número considerável de contribuições de pesquisadores dos Estudos Sociais da Ciência e Tecnologia dos países avançados sobre a participação da comunidade de pesquisa na Política Científica e Tecnológica (PCT).

* Agradeço ao parecerista anônimo da RBCS, pelas recomendações feitas à versão anterior deste trabalho, à Unicamp e ao CNPq, pela possibilidade de realizar a pesquisa que o originou, e aos professores e alunos do Departamento de Política Científica e Tecnológica da Unicamp, pelas discussões que temos tido sobre o tema.

Artigo recebido em abril/2005

Aprovado em abril/2006
Ele é resultado de uma linha de pesquisa orientada à análise da PCT brasileira que tem com foco privilegiado o entendimento do papel dos atores que participam no processo decisório que a conforma. ${ }^{1}$ Seu propósito não é a originalidade, e seu estilo, além de impessoal, procura ser de caráter não-prescritivo. É original, apenas, a forma como se agrupa e descreve as concepções e as posturas assumidas pelos pesquisadores. O recurso à citação de trechos extensos se deve, por um lado, à intenção de transmiti-las fielmente ao leitor; por outro, ao fato de que ao traduzir os textos da língua inglesa se espera poder contribuir no sentido de amenizar a escassez de trabalhos publicados no país sobre o tema abordado. A elaboração do trabalho procurou atender ao que parece ser uma das atividades de pesquisadores de uma determinada área de política pública, situados numa região periférica, a saber, a análise, a partir de sua perspectiva, da evolução do trabalho de colegas que a ela se dedicam nos países avançados. ${ }^{2}$ 
Esse procedimento metodológico tem sido usado por pesquisadores latino-americanos quando desejam analisar políticas ou processos verificados na região, sobre os quais não existe suficiente informação empírica, ou metodologias de trabalho consolidadas ou adequadas para tratar a realidade local; ou mesmo quando as análises disponíveis não parecem ser suficientemente rigorosas do ponto de vista científico. O procedimento consiste numa análise comparativa que, ao mesmo tempo, se orienta à formulação de um marco analítico-conceitual apropriado para o tratamento de nossa realidade periférica. Ao observar processos ou políticas que se verificam nos países avançados (ou as análises que deles se fazem), onde a informação disponível, o número de pesquisadores envolvidos com o tema e os recursos de que se dispõe são significativamente maiores, pode-se depois, "por diferença", relaxando algumas condições de contorno do "caso puro" e introduzindo outras, entender a especificidade do que aqui ocorre. Dessa forma, considerar condicionantes associados à nossa condição periférica que, embora sejam bem conhecidos, não foram ainda "estilizados" a ponto de poderem ser incorporados às análises que desenvolvemos em áreas de política pública como a abordada neste artigo, será possível fortalecer os marcos analítico-conceituais que empregamos.

Seguem-se a esta Introdução uma seção em que se apresenta a visão dos pesquisadores dos países avançados sobre o contexto de mudança que engloba o processo de elaboração da PCT. Nas três seções seguintes, mostrase sua avaliação acerca de como os três atores que participam neste processo - comunidade de pesquisa, burocratas e empresários - estão se reposicionando em função das modificações do contexto. Nas Considerações Finais, tendo como base uma análise do ambiente em que se formam esses atores, levantam-se causas que explicariam a afirmação contida nos trabalhos revisados quanto à baixa probabilidade de que a comunidade de pesquisa venha a perder seu papel dominante. Ao fazê-lo, imprime-se ao trabalho um tom distinto daquele descritivo que o caracteriza e adota-se uma perspectiva crítica em relação àqueles trabalhos, procurando indicar como enfoques ainda pouco utilizados para a análise da PCT poderiam contribuir para elucidar essas causas.

\section{Modo 1 versus Modo 2 e a ruptura mertoniana}

A afirmação radical de que a política de C\&T parece ser, em todo o mundo, a política pública mais eficazmente "capturada" pelo seu ator central a comunidade de pesquisa -, é um dos argumentos centrais que desenvolverei aqui. Embora não possa ser "provado", ela parece encontrar respaldo nos trabalhos de renomados analistas da PCT de países avançados (Gibbons et al., 1994; Nowotny et al., 2001; Etzkowitz, 1989; Webster e Etzkowitz, 1991), que tratam das transformações pela qual passa $\mathrm{O}$ Complexo Público de Ensino Superior e de Pesquisa (CPESP) desses países.

Com o objetivo de potencializar, no campo normativo, a tendência de conformação de um novo arranjo institucional da relação universidade-empresa-governo, eles têm enfatizado o surgimento de um contrato social que levaria a um comportamento mais adequado da comunidade de pesquisa. Ao fazê-lo, referem-se ao "Modo 1", em que a comunidade de pesquisa no âmbito do velho contrato assumia uma posição de extrema influência. Posição esta analisada por Sabatier e Mazmanian (1979), quando verificam como o ator dominante no âmbito de uma determinada política pública pode vir a atuar como se ela fosse de sua "propriedade" (ou o que aludimos acima como "captura").

Para tanto, é necessário indicar como os pesquisadores dos países avançados entendem o processo que estabelece o contexto da mudança. Esse entendimento parte da caracterização do contrato social que vigorou no período de pósguerra. De acordo com Guston e Kenniston, ele pode ser assim sintetizado

[...] o governo promete apoiar a ciência básica que a revisão por pares considerar mais meritória, e os cientistas prometem que a pesquisa será executada bem e honestamente e que proverá um fluxo constante de descobertas que possam ser traduzidas em produtos novos, medicamentos, ou armas (1994, p. 2). 
No final dos anos de 1980 (talvez antes, em países como o Reino Unido e os Estados Unidos), foi sendo estabelecido um novo contrato social em que a comunidade de pesquisa teria que controlar suas demandas por autonomia e recursos crescentes e se comprometer com a implementação de uma agenda de pesquisa explicitamente relacionada a objetivos sociais. Esse contrato social revisado estaria fundado numa expectativa de que,

[...] em troca de fundos públicos, os cientistas e as universidades teriam que orientar sua pesquisa para satisfazer usuários econômica e socialmente significativos. Teriam também que assumir responsabilidades muito mais explícitas do que até então, no sentido de persuadir os políticos e a sociedade do mérito de suas pesquisas, e pautarse por um modelo de inovação muito mais complexo do que o modelo linear previamente adotado (Idem, p. 2).

Gibbons et al. (1994) e Nowotny et al. (2001) se referem da seguinte maneira a esse processo:

[...] a forma como se apresenta a relação entre ciência e política no Modo 1 e no Modo 2 é muito distinta. Ao deixar de ser vista como orientada pela curiosidade e pelo desinteresse, e sim por necessidades estratégicas associadas ao desenvolvimento de redes, e com interesses bem definidos, a ciência adquire um valor político muito distinto. O método científico, entendido como "O" caminho para a busca da verdade, perde grande parte de sua importância. Várias metodologias são utilizadas na busca do conhecimento, e a escolha entre elas passa a ser realizada essencialmente em função de considerações estratégicas e de utilidade.

Referindo-se a outro aspecto central desse processo, Skoie afirma que

[...] a transição do Modo 1 para o Modo 2 demanda uma considerável mudança no que respeita à avaliação e à seleção de propostas. A seleção mediante a revisão por pares, que era uma peçachave do Modo 1, baseava sua força em sua capacidade para premiar a pesquisa acadêmica do mainstream, deixando de lado propostas ruins. Mas, por estar apoiada apenas no "método científico" e não em considerações externas ao ambiente científico, ela não é adequada para selecionar propostas de pesquisas inovadoras: inovações radicais na orientação da pesquisa e pesquisas de alto risco científico tendem a ser rejeitadas pelo julgamento por pares (2001, p. 69).

Na mesma direção, aponta o conhecido sociólogo da ciência, o inglês John Ziman (1990), ao tratar do que ele denomina "uma ciência em mutação numa sociedade em mutação". Ele o sintetiza como uma radical transformação da concepção mertonia$\mathrm{na}^{3}$ da ciência como um espaço social relativamente autônomo, livre das injunções externas de controle social exercidas pela política e pelas autoridades religiosas; um espaço em que mecanismos institucionais internos de controle da qualidade permitiam que somente os "pares" pudessem julgar o trabalho científico e que teve como resultado o surgimento do "ethos acadêmico", que passou a conformar normas de comportamento profissional, motivações e atitudes.

A síntese sugerida por Ziman (1990) para referir-se à transformação em curso na direção do que denomina "cultura pós-acadêmica" estaria caracterizada por uma substituição da norma do comunalismo pela ciência proprietária; da universalidade pela ciência local; do desinteresse pela ciência autoritária; da originalidade pela ciência comissionada; e do ceticismo pela ciência "especializada" (expert). Nesse novo ethos, a avaliação da qualidade por pares e a liberdade na escolha individual dos temas de pesquisa vão sendo substituídas por uma "contabilidade" (accountability) mais ampla da "excelência" e pela adoção coletiva de uma agenda estabelecida em função de interesses econômicos que deixa de dar origem a bens públicos (comunalismo) e passa a produzir "propriedade intelectual". Valores "não-científicos" de natureza societária, como segurança, rentabilidade e eficácia, passam a participar explicitamente da determinação da agenda de pesquisa.

\section{Especialistas versus burocratas e elaboração das políticas}

Enveredando por um caminho paralelo, Bertilsson (2001) chama a atenção para o fato de que a transição do Modo 1 para o Modo 2 estaria tendo como resultado um processo de burocrati- 
zação da pesquisa. Estariam surgindo "pesquisadores-burocratas" nos países da Europa, que, segundo o autor, apresentariam vantagens em relação aos cientistas tradicionais. Este processo, entretanto, não implicaria a não formação de laços sólidos entre eles, nem que a própria comunidade acadêmica não seguiria influenciando na definição das características da PCT.

As análises mencionadas, situadas no nível macro dos processos de mudança (de longo prazo e mais ou menos auto-organizados) na relação entre ciência, tecnologia e sociedade, têm influenciado as ações de governo, em particular no que respeita à relação entre os especialistas ${ }^{4}$ e a sociedade.

Para entender como se tem verificado essa influência, é importante levar em conta a discussão que se inicia em meados dos anos de 1990, no âmbito da Comunidade Européia, sobre a crescente complexidade dos problemas que demandavam políticas públicas e os desafios de credibilidade e legitimidade que os governos e outras instituições reguladoras estavam enfrentando. Discussão esta que transcorre numa conjuntura em que modos novos de governança, que proporcionavam mais transparência e prestação de contas (accountability) para os cidadãos, começavam a substituir os modelos top-down centralizadores e não-adequados a sociedades com graus crescentes de diversidade, complexidade, interdependência e incerteza (Boudourides, 2003).

O fato de essa discussão ser entendida como conectada ao "déficit de democracia" europeu, e o fato de este ser visto como resultado da participação de atores políticos não diretamente associados aos cidadãos - lobistas, burocratas, dirigentes nãoeleitos e também de especialistas - explicitou-se a necessidade de contar com modos de governança que inibissem a influência excessiva desses atores na elaboração de políticas. Ganhou força, então, a idéia de que a melhor forma de fazê-lo era estimular esses atores (inclusive os especialistas) a assumir explicitamente seus interesses e responsabilidades e a participar em formas interdependentes e interativas de elaboração de políticas baseadas em processos de cooperação, negociação ou conflito, de modo a resolver problemas e criar novas oportunidades para a sociedade.

A importância que o papel do conhecimento no processo de elaboração de políticas passou a ter nesse contexto conduziu a uma preocupação cada vez maior com a democratização das expertises $^{5}$ e com uma melhor compreensão de como elas estavam sendo usadas pelos governos europeus, o que deu lugar ao estabelecimento de normas para sua seleção e uso, visando ao aumento da participação dos cidadãos nos processo de decisão em que intervêm os atores - especialistas e tomadores de decisão (policy makers) - que usualmente monopolizam esses processos.

Katy Whitelegg (2003) oferece um quadro detalhado da transformação que vem ocorrendo nos últimos dez anos nas estruturas de aconselhamento científico (scientific advisory structures) europeu. Abordando quinze países, ela mostra como esse processo tem estado condicionado pelo debate acerca do papel cambiante da ciência e das instituições científicas (universidades, centros de pesquisa) na sociedade e pela necessidade de contar com novas formas de apoio cognitivo aos processos de decisão envolvidos na elaboração das políticas. Comparando os processos protagonizados pela Hungria e Áustria, que partem de situações prévias bastante distintas no que tange ao contexto socioeconômico e político-institucional, a autora ilustra como os países do Leste europeu parecem estar sendo mais bem-sucedidos no processo de transformação das instituições políticas e dos sistemas de pesquisa. E, em conseqüência, como tendem a alcançar níveis de robustez e transparência maiores em suas estruturas de aconselhamento científico. É interessante observar que esses países, em função de sua história política, por terem que conceber de modo democrático e participativo estruturas que praticamente inexistiam, e por não terem que enfrentar interesses estabelecidos, parecem ter alcançado, senão ultrapassado, os padrões vigentes nos países da União Européia. ${ }^{6}$

Vários pesquisadores têm assinalado a mudança da situação que vigorava até recentemente nos países avançados, em que os especialistas desempenhavam um papel praticamente exclusivo de prover fundamento científico para a elaboração das políticas públicas. Papel este que foi sintetizado na arguta expressão "falando a verdade para o poder" de Aaron Wildavsky (1979). Lançando mão desta expressão, Hoppe (1999) sintetiza sua análise sobre a mudança na relação entre os especia- 
listas e o governo com um jogo de palavras que intitula seu artigo: "De "falando a verdade para o poder' para 'fazendo sentido junto'". Outros autores, como Jasanoff (2000), têm igualmente argumentado que esse papel tradicional já não é uma descrição correta da nova relação que se desenha entre ciência e política.

Também analisando essa mudança, Whitelegg (2003) aponta quatro fatores que estariam na sua origem: a velocidade e o impacto potencial do desenvolvimento tecnológico; o aumento da incerteza no âmbito da própria ciência e de suas implicações para a sociedade; a maior complexidade do processo de elaboração de políticas que, cada vez mais, se apóia em processos explícitos de negociação entre os atores com eles envolvidos; e o novo contrato que está emergindo entre a esfera da produção de conhecimento e a sociedade.

\section{Especialistas versus empresários e agenda de pesquisa}

Num contexto marcado por uma legítima expectativa de que as mudanças em curso levem à inclusão de atores que contribuam para desbloquear a agenda do processo decisório da PCT, alguns autores, que adotam um viés descritivo baseado em pesquisa empírica, merecem destaque.

Um deles é Enno Aufderheide (2001), do Conselho Científico Alemão, que analisou o processo decisório e as estruturas de tomada de decisão acerca de prioridades de pesquisa, no interior dos Conselhos de Pesquisa europeus. Segundo ele, na maior parte desses conselhos, seja por imposição legal (Alemanha e Dinamarca, por exemplo), seja por delegação do primeiro-ministro, que é quem formalmente ocupa sua presidência (Reino Unido e Finlândia, por exemplo), sua coordenação é ocupada por um cientista. No caso da Holanda único país com um presidente de conselho em tempo integral -, são também os cientistas que, por tradição, ocupam este cargo (embora empresários e políticos também tenham presidido o conselho).

Comentando a respeito da participação dos empresários, vários autores dão a entender que sua influência não é maior do que a dos outros dois atores - burocratas e políticos - que, junto com a comunidade de pesquisa, participam do processo de tomada de decisão da C\&T. Referindo-se ao caso do Reino Unido, Maureen Gardiner (2001), representante de um importante centro de pesquisa privado britânico, afirma que o papel do comércio e da indústria na orientação da agenda de pesquisa é ainda "pouco sofisticado e inseguro". Referindo-se à Alemanha, é novamente Aufderheide (2001) que aponta que, embora exista um número crescente de empresas privadas atuando no campo da política de C\&T, isso não tem provocado uma mudança sensível no modo como se dá o processo decisório.

Além disso, parece ser ainda pequena a evidência empírica disponível para dar suporte ao argumento de que a comunidade de pesquisa estaria atuando de forma pró-ativa e mais aderente às tendências que, desde há quase três décadas, segundo vários pesquisadores, vêm-se manifestando nos países avançados. Talvez a pesquisa mais exaustiva nesse sentido tenha sido a realizada no âmbito do Projeto "A Administração da Pesquisa em Transformação", promovido pelo Instituto Dinamarquês para Estudos sobre a Pesquisa e a Política de Pesquisa. Envolvendo uma significativa amostra - vinte institutos públicos de pesquisa (mil respondentes válidos) e todas as universidades do país (quase 3 mil respondentes válidos) -, a pesquisa avaliou, entre 1998 e 2001, a opinião dos pesquisadores sobre as mudanças introduzidas nos instrumentos de administração da pesquisa durante os dez anos que a antecederam.

De uma forma geral, concluiu-se que, embora os pesquisadores estivessem abertos a colaborar com a indústria, alterando sua agenda de pesquisa, eles não estavam dispostos a aceitar regras criadas pelo governo que limitassem sua "liberdade de pesquisa". Em particular, e revelando a maior importância que conferiam às questões de forma em relação às de conteúdo, eles se mostraram especialmente preocupados em manter sua liberdade para escolher os métodos de realização de suas pesquisas (Langberg, 2001).

Outra interessante pesquisa também realizada na Dinamarca, desta vez dirigida aos empresários, tomou uma amostra de 31 empresas que apresentavam significativos laços de cooperação com universidades. Seu objetivo era entender por que, apesar de uma grande quantidade de trabalhos empíricos realizados no país apontarem que os empresários 
davam muita importância àquela cooperação (confirmando, portanto, as hipóteses contidas na visão do Modo 1 versus Modo 2 e da Hélice Tripla), tão pouco podia ser de fato comprovado nesse sentido.

No trabalho que sintetiza o resultado dessa pesquisa, Schmidt (2003) cita uma outra, cujos resultados lhe serviram de "hipótese nula". Baseada em entrevistas com seiscentos gerentes de pesquisa de empresas privadas, essa pesquisa mostrou que $40 \%$ deles consideravam o conhecimento das instituições públicas de pesquisa importante, e que, entre os que desenvolviam pesquisas em colaboração, $60 \%$ possuíam a mesma opinião? ${ }^{7}$

Schmidt (2003) agrupou essas barreiras que dificultavam a relação universidade-empresa em vários tipos: estruturais, contextuais, institucionais (legislação, regulamento e políticas) e culturais (cultura profissional, normas e valores). Os resultados mais interessantes se referem a esses últimos tipos. Sobre as universidades, concluiu-se que elas são sistemas fechados, pouco interessados na cooperação com empresas, nem na comercialização de resultados de pesquisa; que possuem formas de organização burocráticas, ineficientes e inflexíveis e que por isso têm dificuldade para cooperar com empresas; que a pesquisa pública é lenta e muito intensiva em tempo; e que não possui mecanismos de recompensa que motivem os pesquisadores relacionados com empresas. Sobre os pesquisadores universitários, chegou-se à conclusão que eles "não entendem o corporativismo e não estão interessados em entender" e que superestimam o valor econômico e científico-tecnológico dos resultados de sua pesquisa.

\section{A reação dos especialistas}

O questionamento de burocratas e empresários acerca da posição quase hegemônica dos especialistas na elaboração da PCT tem originado uma reação que, apesar de difusa e não concertada, pode ser claramente identificada pelos pesquisadores do campo dos Estudos Sociais da Ciência e Tecnologia.

Morris (2001), baseando-se em entrevistas com 74 pesquisadores universitários da área de biomédica, realizadas no Reino Unido, mostrou que, embora os pesquisadores conhecessem muito bem as políticas das instituições de fomento, sua interpretação sobre a validade destas estava claramente condicionacda a seus interesses particulares. Assim, eles se preoupavam demasiadamente com a possibilidade de que elas determinassem sua agenda de pesquisa e alocassem recursos de forma contrária a seus interesses. Não obstante, entendiam que tais políticas estavam dentro de certos limites considerados controláveis. Eles também atribuíam as mudanças no seu comportamento em direção à interdisciplinaridade ou à colaboração externa às novas tendências do avanço científico, mais do que à influência dessas políticas. Criticavam, além disso, o descompasso entre as estruturas das instituições burocráticas e as necessidades que apresentavam os pesquisadores para o desenvolvimento de suas pesquisas.

Essa pesquisa apresenta um resultado extremamente importante para a avaliação tanto das dificuldades que cercam a transição que se está analisando, como da eficácia das políticas para levá-la a efeito. Trata-se da recomendação que se faz em relação à formulação e à implementação da PCT, no sentido de que se

[...] avalie até que ponto os cientistas (como agentes) podem desviar ou subverter as intenções dos formuladores das políticas (e em que medida este processo envolve algum tipo de colusão) e quais mecanismos ou processos poderiam, baseados nesta evidência, pavimentar o caminho de ida-evolta, que vai da intenção ou dos objetivos das políticas até os lugares onde é implementada (Morris, 2001, p. 139).

Ainda no âmbito das dificuldades que estariam ocorrendo para que a transição para o Modo 2 pudesse ocorrer com a intensidade prevista ou desejada, Siune e Aagaard (2003) abordam uma condição consensualmente considerada central para os interessados, seja em objetivos econômicos, seja em objetivos sociais ou cognitivos, a saber, a interdisciplinaridade. Com base em uma extensa revisão da bibliografia existente nos países avançados sobre o tema, as autoras apontam os vários tipos de dificuldade que as universidades desses países enfrentam para cumprir o objetivo da interdisciplinaridade. As sete condições apresentadas como recomendações (os sete pilares do sucesso da cross-disciplinarity) dão bem uma idéia da dimensão do problema. 
Apoiando-se em opiniões de dois importantes personagens do ambiente de pesquisa europeu - Steve Rayner, do Conselho de Pesquisas Sociais e Econômicas britânico, e Joachim Nettelbeck, do Instituto de Estudos Avançados alemão -, Siune e Aagaard (2003) mostram-se pouco confiantes acerca da viabilidade do que denominam o "futuro sem disciplinas do Modo 2". Segundo elas, parece ser contraditório pensar que a universidade atual seja capaz de se orientar na direção da interdisciplinaridade. Isto porque ela depende, de um lado, da existência de um conhecimento disciplinar a um só tempo robusto e permeável - além do que se trata de uma habilidade particular que germina em nichos especializados na periferia de disciplinas estabelecidas, e, de outro lado, de pesquisadores suficientemente seguros de seu conhecimento disciplinar para se aventurarem nesses nichos. Estabelecer um sistema de "prêmio e castigo" que dê conta desses dois movimentos é especialmente difícil.

Outro ponto que tem sido levantado é a postura da comunidade de pesquisa em relação às políticas implementadas pelos governos com o objetivo de potencializar os aspectos positivos e desejáveis das mudanças em curso. De acordo com Gronbaek (2001), as reações da comunidade de pesquisa européia, embora difiram segundo as disciplinas, indicam uma resistência contra as tendências contemporâneas. Metodologias, como as de "planejamento estratégico" (strategy-planning) e "identificação de prioridades" (priority-setting), empregadas pelos conselhos de pesquisa, têm transformado suas condições de trabalho de maneira indesejável. Segundo Skoie (2001), os pesquisadores têm afirmado não ser necessário fazer com que os recursos alocados pelo governo fluam pelos Conselhos de Pesquisa. E que os recursos poderiam ser alocados diretamente para os institutos de pesquisa sem que fosse necessário estabelecer um sistema baseado em conselhos de pesquisa.

Outros pesquisadores destacam a existência de importantes forças que contrabalançam as tendências atuais. Etzkowitz e Leydesdorff (1997), por exemplo, assinalam que, ao longo de sua história, a universidade tem-se mostrado bastante adaptável às mudanças de contexto, mantendo uma participação ativa em processos de co-organização como os que atualmente se observa. Mas os autores acreditam, também, que o processo em curso não será capaz de conduzir a uma situação que leve a um comportamento uniforme da comunidade de pesquisa ante a PCT. Segundo eles, tal processo dará lugar a pelo menos cinco espécies novas ou híbridas, cada uma gerada por meio da hipertrofia de algum dos aspectos que hoje se manifestam.

Ziman (1990) aponta, num outro sentido, para a preocupação que tem demonstrado a comunidade de pesquisa em continuar levantando bem alto o estandarte da sua imparcialidade. Sua competência técnica, e mais do que isto, sua sabedoria, a posicionaria em condições de arbitrar, com a neutralidade e a legitimidade social necessárias, os eventuais conflitos que a ciência pós-acadêmica tenderia cada vez mais a provocar com os interesses do conjunto da sociedade.

\section{Considerações finais}

Ao terminar essa revisão sobre as avaliações realizadas por pesquisadores de países avançados acerca das transformações que estariam ocorrendo na relação entre ciência, tecnologia e sociedade, vale a pena retomar Nowotny et al. (2001). Ao referirem-se à(s) "comunidade(s) científica(s)", eles enunciam o que consideram seus elementos centrais: composição cada vez mais heterogênea, valores cada vez mais contestados, métodos mais variados, limites mais indefinidos. Contudo, chamam a atenção para o quanto a comunidade científica pode ainda ser distinguida dos domínios da cultura, da economia e da sociedade. Ressaltam, dessa forma, a perspectiva dominante de que a "cientifização" da sociedade não minimizou o papel da comunidade científica no mundo, ainda que a tenha obrigado a enfrentar um mundo cada vez mais complicado. Embora reconheçam o fato de a "ciência ter penetrado, e ter sido penetrada, pela sociedade", os autores consideram que isso não implicou aceitar a existência de "uma mão invisível guiando a evolução da ciência e da sociedade em paralelo; co-evolução seria um aspecto da coalescência" (Idem, p. 49).

A posição desses autores contém um aspecto paradoxal que aparece também em outros trabalhos analisados neste artigo. A comunidade de pesquisa estaria, por um lado, aceitando delegar uma 
parte de seu poder de definição da agenda de pesquisa a outros atores - empresários, burocratas, políticos e movimentos sociais. Tendência compreensível tendo em vista a crescente "densidade" e "completude" do tecido social dos países avançados, que emite um "sinal de relevância crescentemente audível e legítimo" (Dagnino, 2004). Mas, por outro, estaria pleiteando um lugar ainda mais privilegiado num outro espaço institucional distinto daquele onde se dá o processo decisório que origina a alocação de recursos. Um espaço em que ela ainda possuiria uma vantagem comparativa e quase exclusiva - o conhecimento - para arbitrar conflitos entre os demais atores envolvidos com a PCT e, principalmente, evitar rupturas ou inflexões em sua trajetória que contrariem seus interesses.

A situação é, pois, paradoxal, o que não quer dizer que se trata de uma contradição. A comunidade de pesquisa, ao mesmo tempo em que abriria caminho a mudanças que diminuiriam a dimensão ativa e explícita do seu poder, buscaria uma progressão segura pela via da valorização de uma instância de resolução de conflitos de interesse, em que a dimensão implícita do seu poder cognitivo estaria assegurada.

Cabe registrar a ausência nas contribuições dos autores analisados de algo que explique por que consideram a escassa a probabilidade de que venha a diminuir o papel dominante que a comunidade de pesquisa possui no processo de elaboração da PCT. Essa deficiência talvez possa ser explicada pela natureza dos enfoques que utilizam esses autores (Dagnino, 2005). Para saná-la, creio que o emprego do instrumental da Análise de Política, ainda pouco explorado pelos analistas da PCT de países avançados, poderia auxiliar. Esse enfoque adicionaria elementos de natureza política (policy e politics) para o entendimento do comportamento da comunidade de pesquisa vis-à-vis os demais atores - burocratas e empresários - presentes no cenário da PCT. Tal comportamento poderia ser explicado pela sua capacidade de disseminar $^{8}$ na sociedade e, por inclusão, junto àqueles atores, sua visão acerca do desenvolvimento da C\&T, baseada nas idéias de neutralidade da ciência e de determinismo tecnológico (Feenberg, 2002; Lacey, 1999; Broncano, 1995; Dagnino, 2002).
Essa visão dominante não é conveniente apenas para a comunidade de pesquisa. Endossando-a no cenário da PCT, os outros dois atores podem deixar implícitos seus verdadeiros interesses em relação à orientação que deveria seguir o desenvolvimento da ciência e da tecnologia. Um ligeiro exame seria suficiente para mostrar o hiato existente entre essa visão instrumental e otimista (a ciência, intrinsecamente verdadeira, e a tecnologia, cada vez mais eficiente, se secundadas pela ética nunca seriam usadas "para o mal") e os interesses de burocratas e empresários. De fato, tanto os interesses dos burocratas - relativos ao bom funcionamento da máquina estatal e à satisfação das necessidades sociais ou das suas demandas corporativas como os dos empresários - relativos a subsídios para a formação de recursos humanos e à Pesquisa e Desenvolvimento que aumenta a lucratividade de seus negócios - poderiam ficar protegidos por aquela visão.

Em contrapartida, o fato de que essa visão constitui o fundamento da matriz cognitiva do ensino e da pesquisa universitária - vale lembrar que a universidade é justamente o lugar onde aqueles dois atores são formados, conformando o ethos no qual eles são socializados - é um poderoso elemento unificador que explica o seu comportamento, o baixo grau de dissenso ${ }^{9}$ que caracteriza a PCT e, em última análise, o predomínio da comunidade de pesquisa na sua elaboração.

\section{BIBLIOGRAFIA}

AUFDERHEIDE, E. (2001), "The role of science councils as advisory bodies in national science policy priority setting", in K. Siune (coord.), Science policy: setting the agenda for research, proceedings from Muscipoli, Dinamarca, The Danish Institute for Studies in Research and Research Policy.

BACHRACH, P. \& BARATZ, M. S. (1962), "Two faces of power". American Political Science Review, 56: 947-952.

BERTILSSON, M. (2001), "From honoratiores to bureaucrats: research counceling in transition”, in K. Siune (coord.), Science policy: setting the agenda for research, procee- 
dings from Muscipoli, Dinamarca, The Danish Institute for Studies in Research and Research Policy.

BOUDOURIDES, M. (2003), Governance in science $\varepsilon$ technology. UK, University of York, Conference Responsibility Under Uncertainty, jul.-ago.

BROCANO, F. (1995), Mundos artificiales: filosofía del cambio tecnológico. México, Paidós.

DAGNINO, R. (1997), "Identificação de prioridades de P\&D e objetivos nacionais nos países da OECD: tempo de reabrir o debate?". Planejamento e Políticas Públicas, 16: 137-162, Brasília, Ipea.

(2002), "Enfoques sobre a relação ciência, tecnologia e sociedade: neutralidade e determinismo". Trabalho apresentado na Organização dos Estados Iberoamericanos para a Educação, a Ciência e a Cultura, Sala de Lectura CTS+I de $1^{\text {a }}$ OEI, disponível no site http://www.campusoei.org/salactsi/index.html.

(2003a), "O processo decisório no complexo público de ensino superior e de pesquisa: uma visão de análise de política”. Redes, 10 (20): 27-42, dez., Buenos Aires.

(2003b), "A relação universidadeempresa no Brasil e o "argumento da hélice tripla". Revista Brasileira de Inovação, 2 (2): 267-308, jul.-dez., Rio de Janeiro, Finep.

(2004), "A relação pesquisa-produção: em busca de um enfoque alternativo", in L. Santos et al., Ciência, tecnologia e sociedade: o desafio da interação, Londrina, Iapar, pp. 103-146.

(2005), "Enfoques empregados nos países avançados para a análise da política de ciência e tecnologia". Campinas, Unicamp, Departamento de Política Científica e Tecnológica (mimeo.).

DAGNINO, R. \& GOMES, E. (2003), "O processo decisório na universidade pública brasileira: uma visão de análise de política", in J. Dias Sobrinho e I. Dilvo Ristoff, Avaliação e compromisso público, Campinas, Insular, pp. 159-187.

DAGNINO, R. \& THOMAS, H. (1999), "Latin American science and technology policy: new scenarios and the research community". Social Studies of Science, 4 (1): 3554, Nova Déli.

ETZKOWITZ, H. (1989), "Entrepeneurial science in the academy: a case of transformation of norms". Social Problems, 36 (1): 14-29.

ETZKOWITZ, H. e LEYDESDORFF, L. (eds.). (1997), Universities and the global knowledge economy: a triple helix of universityindustry-government relations. Londres, Cassell Academic.

FEENBERG, A. (2002), Transforming technology. Londres, Oxford University Press.

GARDINER, M. (2001), "Setting the research agenda: the industrial/commercial perspective", in K. Siune (coord.), Science policy: setting the agenda for research, proceedings from Muscipoli, Dinamarca, The Danish Institute for Studies in Research and Research Policy.

GIBBONS, M. et al., (1994), The new production of knowledge: the dynamics of science and research in contemporary societies. Londres, Sage.

GRONBAEK. D. (2001), "Adapting research councils to strategic priority-setting: the case of Denmark", in K. Siune (coord.), Science policy: setting the agenda for research, proceedings from Muscipoli, Dinamarca, The Danish Institute for Studies in Research and Research Policy.

GUSTON, D. H. \& KENISTON, K. (eds.). (1994), The fragile contract. Cambridge/Londres, MIT Press.

HAM, C. \& HILL, M. (1993), The policy process in the modern capitalist State. Nova York, Harvester Wheatshesf.

HOPPE, R. (1999), "Policy analysis, science and politics: from 'speaking truth to power' to 'making sense together'". Science and Public Policy, 26 (3): 201-210, jun. 
JASANOFF, S. (2000), "Science and governance: the US experience". IPTS Report, 45. Disponível no site http://www.jrc.es/pages/iptsreport/vol45/english/JASANOFF455.htm.

LACEY, H. (1999), Is science value-free? Values and scientific understanding. Londres, Routledge.

LANGBERG, K. (2001), “'Researchers' reactions to and perceptions of policymaking instruments", in K. Siune (coord.), Science policy: setting the agenda for research, proceedings from Muscipoli, Dinamarca, The Danish Institute for Studies in Research and Research Policy.

MERTON, R. K. (1980), "Los imperativos institucionales de la ciencia", in B. Barnes (ed.), Estudios de sociología de la ciencia, Madri, Alianza.

MORRIS, N. (2001), "The effect of research council policies on researchers choices", in K. Siune (coord.), Science policy: setting the agenda for research, proceedings from Muscipoli, Dinamarca, The Danish Institute for Studies in Research and Research Policy.

NOWOTNY, H. et al. (2001), Re-thinking science: knowledge and the public in an age of uncertainty, Cambridge, Polity Press/ Blackwell Publishers Inc.

SABATIER, P. \& MAZMANIAN, D. (1979), "The conditions of effective implementation: a guide to accomplishing policy objectives". Policy Analysis, 5 (4): 481-504.

SCHMIDT, E. (2003), "Science and society: building bridges of excellence perceptions on the interaction between public research and enterprises". Disponível no site http://www.afsk.au.dk/ftp/ScienceSociety /2003_6.pdf.

SIUNE, K. \& AAGAARD, K. (2003), "Science policy as a frame for cross disciplinary research". Research Management Processes under Rapid Change Report from The Danish Institute for Studies in Research and Research Policy, Copenhague.
SKOIE, H. (2001), "The research councils in the Nordic countries: developments and some challenges", in K. Siune (coord.), Science policy: setting the agenda for research, proceedings from Muscipoli, Dinamarca, The Danish Institute for Studies in Research and Research Policy.

WEBSTER, A. J. \& ETZKOWITZ, H. (1991), "Academic-industry relations: the second academic revolution?". Londres, Science Policy Support Group (SPSG concept paper n. 12).

WHITELEGG, K. (2003), "The transformation of scientific advisory structures in the unifying Europe: a comparison of recent developments in Hungary and Austria". Paper for the Innovation in Europe: dynamics, institutions and values, Roskilde, maio 8-9.

WILDAVSKY, A. (1979), Speaking truth to power: the art and craft of policy analysis. Boston, Little Brown.

ZIMAN, J. M. (1990), "What is happening to science?", in S. E. Cozzens et al. (eds.), The research system in transition, Dordrecht, Kluwer Academic, pp. 23-33.

\section{Notas}

1 Fazem parte do resultado dessa linha de pesquisa os trabalhos de Dagnino (2003a e b; 2005), Dagnino e Thomas (1999) e Dagnino e Gomes (2003).

2 Um exemplo de análise com esse objetivo num campo correlato ao explorado neste trabalho, sobre a utilização de metodologias de identificação de prioridades de pesquisa pelos países avançados, encontra-se em Dagnino (1997).

3 Robert Merton, em 1942, "codifica" o pensamento dominante acerca da "concepção ideal" de cientista. Inspirado no conceito de "burocrata ideal" e do decálogo concebido por Weber, ele propõe as cinco normas da atividade científica que regeriam o comportamento da comunidade de pesquisa (Merton, 1980).

4 Optou-se por utilizar a expressão "especialistas" (experts) sem estabelecer uma diferenciação com a 
de comunidade científica ou de pesquisa, porque é a que aparece com maior freqüência nos trabalhos consultados.

5 Preferimos manter a expressão em inglês a adotar a tradução feita por autores de língua espanhola expertícias - ou ainda usar um termo genérico como "saberes".

6 Embora fuja ao objetivo deste trabalho, vale apontar que países como o Brasil, que não possuem uma estrutura formal de apoio cognitivo aos processos de decisão envolvidos na elaboração das políticas e que pretendem ingressar numa etapa de maior transparência e responsabilidade governamental, talvez possam se beneficiar da experiência do Leste europeu.

7 Ainda que novamente fora de lugar, é interessante citar, para efeito de comparação, o resultado de duas pesquisas recentes realizadas no Brasil. Uma delas mostra que, enquanto $71 \%$ das empresas locais declararam que a aquisição de máquinas e equipamentos mais atualizados é a sua principal estratégia de desenvolvimento tecnológico, apenas $3 \%$ apontaram a absorção de pesquisadores pela empresa e que as universidades e os institutos de pesquisa públicos ou privados foram citados em $10^{\circ}$ e $11^{\circ}$ (penúltimo) lugar entre as fontes de conhecimento. A segunda mostra que entre as empresas inovadoras paulistas somente $1,5 \%$ consideram importante a relação com universidades e institutos de pesquisa.

8 Ham e Hill (1993) chamam a atenção para situações em que a consecução dos objetivos de atores dominantes é facilitada (e o seu poder aumentado) pela incorporação ao senso comum de idéias e valores por eles gerados ou disseminados mediante processos referidos como mobilisation of bias, influence of interests over the agenda-setting process ou elite control of the debate.

9 O que Bachrach e Baratz (1962) denominaram non-decison making. 


\section{A COMUNIDADE DE PESQUISA DOS PAÍSES AVANÇADOS E A ELABORAÇÃO DA POLÍTICA DE CIÊNCIA \& TECNOLOGIA}

\section{Renato Dagnino}

Palavras-chave: Comunidade de pesquisa; Política de ciência e tecnologia; Estudos sociais da ciência e tecnologia; Países avançados.

Este texto trata da percepção dos pesquisadores de países avançados que analisam as transformações pelas quais está passando o ambiente da pesquisa e do ensino superior acerca do papel da comunidade de pesquisa (vis-à-vis burocratas e empresários) na elaboração da política a ele concernente. Além de proporcionar uma visão de conjunto compreensiva e atualizada sobre o tema a colegas latino-americanos, $\mathrm{O}$ autor pretende mostrar que muitas das características de nossa comunidade parecem estar igualmente presentes, às vezes de forma atenuada, naqueles países. Espera-se, assim, contribuir para que elas sejam consideradas nos processo de elaboração da política de ciência e tecnologia de nossos países.

\section{RESEARCH COMMUNITY AND SCIENCE AND TECHNOLOGY POLICY IN DEVELOPED COUN- TRIES: A LATIN AMERICAN PERS- PECTIVE}

Renato Dagnino

Keywords: Research community; Science and technology policy; Latin America; Science and technology studies.

The work approaches the perception of advanced countries researchers who analyze the transformation in course in the research and higher education institutions concerning the research community's role (vis-à-vis the bureaucrats and entrepreneurs) in their policy making process. Its objective, besides providing an updated panoramic vision on the theme for Latin-American colleagues, is to show that many of our community's characteristics seem to be equally present, sometimes in a lessened way, in those countries. The aim of the work is to contribute to a more adequate consideration of these characteristics in the elaboration of the Science and Technology policy of our countries.

\section{LA COMMUNAUTÉ DE RECHER- CHE DES PAYS AVANCÉS ET L'ÉLABORATION DE LA POLITI- QUE DES SCIENCES ET DE LA TECHNOLOGIE}

Renato Dagnino

Mots-clés: Communauté de recherche; Politique des Sciences et de la Technologie; Études sociales des sciences et de la technologie; Pays développés.

Ce texte aborde la perception des chercheurs de pays développés qui analysent les transformations subies par l'environnement de la recherche et de l'enseignement supérieur à partir du rôle de la communauté de recherche (vis-à-vis les bureaucrates et les hommes d'affaires) dans l'élaboration de la politique qui les concerne. L'auteur propose une compréhension d'ensemble et actuelle de ce sujet à ses collègues latino-américains. Il tente de démontrer que plusieurs des caractéristiques de notre communauté semblent être également présentes - parfois de façon plus faible - dans ces pays. L'auteur entend, ainsi, contribuer à ce qu'elles soient considérées dans les processus d'élaboration de la politique des sciences et de la technologie de nos pays. 